\title{
BMJ Open Social capital and peer influence of tobacco consumption: a cross-sectional study among household heads in rural Uttar Pradesh, India
}

\author{
Md Zabir Hasan (D) , ${ }^{1}$ Joanna E Cohen (D) , ${ }^{2,3}$ David Bishai (D) , ${ }^{4}$ \\ Caitlin E Kennedy (D) , ${ }^{1}$ Krishna D Rao (D) ,, 1 Akshay Ahuja (D) , ${ }^{5}$ Shivam Gupta (D) ${ }^{1}$
}

To cite: Hasan MZ, Cohen JE, Bishai D, et al. Social capital and peer influence of tobacco consumption: a cross-sectional study among household heads in rural Uttar Pradesh, India. BMJ Open 2020;10:e037202. doi:10.1136/ bmjopen-2020-037202

- Prepublication history and additional material for this paper are available online. To view these files, please visit the journal online (http://dx.doi. org/10.1136/bmjopen-2020037202).

Received 23 January 2020 Revised 18 April 2020 Accepted 29 May 2020
Check for updates

(C) Author(s) (or their employer(s)) 2020. Re-use permitted under CC BY-NC. No commercial re-use. See rights and permissions. Published by BMJ.

For numbered affiliations see end of article.

Correspondence to Dr Md Zabir Hasan; zabir.hasan@gmail.com

\section{ABSTRACT}

Objective Having the world's second-largest tobaccoconsuming population, tobacco control is a priority agenda of the Indian Government. Yet, there is no evidence of how peer influence and nature of social relationships-defined as social capital-affect tobacco use. This study aimed to explore the role of social capital and peer influence on tobacco consumption among household heads in rural Uttar Pradesh (UP), India.

Design and setting This study was embedded within the baseline evaluation of Project Samuday. A cross-sectional multistage cluster survey was implemented in six census blocks of Hardoi and Sitapur districts of UP from June to August 2017. Self-reported tobacco consumption status of randomly selected 6218 household heads ( $\geq 18$ years; men vs women $=5312$ vs 906) was assessed from 346 rural communities. Peer influence of tobacco use was measured by the non-self cluster proportion of tobacco consumption among respondents. Community engagement, social support, trust and social cohesion were separately measured as unique facets of social capital both at individual and community levels using the Shortened Adapted Social Capital Assessment Tool in India (SASCAT-I). The explanatory power of covariates was assessed using gender-stratified generalised estimating equations (GEE) with robust-variance estimator. Result Tobacco consumption patterns were starkly different for men and women ( $71 \%$ vs $14 \%)$. The peer influence only affected men (adjusted odds ratio $(\mathrm{AOR})=1.10,95 \% \mathrm{Cl}: 1.05$ to $1.16, \mathrm{p}<0.01)$, whereas women were more likely to consume tobacco if they were more engaged with community organisations $(A O R=1.33$, $95 \% \mathrm{Cl}=1.07$ to $1.66, \mathrm{p}<0.01$ ).

Conclusion Gender alters the way social engagement affects tobacco use in rural India. Countering peer influence on Indian men should be prioritised as a tobacco control strategy. Moreover, as gender mainstreaming is a critical egalitarian agenda in India, further research is needed to understand how social engagement affects tobacco consumption behaviours among women.

\section{INTRODUCTION}

According to the WHO, in 2016, globally, more than 1.1 billion people smoked tobacco, and $80 \%$ of them are living in low
Strengths and limitations of this study

- This study is first of its kind to integrate two established theoretical frameworks of social science, social cognitive theory and social capital theory, to explore the role of social capital, and peer influence on tobacco use among household heads in rural Uttar Pradesh, India.

- A large randomised sample of respondents, a holistic conceptual framework, use of a validated social capital measurement tool and implementation of multilevel confirmatory factor analysis are few of the significant strengths of this study.

- Self-reported behaviour and actual tobacco consumption pattern can be different for the respondents.

- Due to limited data availability, some known predictors of tobacco use have not been accounted for in the analysis, such as substance abuse, existing comorbidity (eg, diabetes, hypertension), psychological stressors (eg, depression, anxiety) and tobacco control programmes at the community level.

and middle-income countries. ${ }^{1}$ Having 266 million current tobacco users $(21.4 \%$ smokeless and $10.7 \%$ smoked tobacco), India ranks second in tobacco consumption in the world. ${ }^{2}$ Among the northern states, Uttar Pradesh (UP) has one of the highest prevalence of tobacco use (35.5\%; men vs women $=52.1 \%$ vs $17.7 \%)$. Sixteen years since India signed WHO's Framework Convention on Tobacco Control and 7 years after adopting a national action plan and monitoring framework for the prevention and control of noncommunicable diseases (NCDs), progress at reducing tobacco use in UP is still slow. ${ }^{34}$ While a national goal of a $15 \%$ relative reduction was set by 2020, UP observed a $1.5 \%$ increase in tobacco use in the 6 years since 2010. ${ }^{5}$

Determinants of tobacco consumption exist at the individual, community and societal 
levels. At the individual level-being men, unmarried, belonging to older age groups, with lower education and wealth independently predicts higher tobacco use. ${ }^{6-8}$ Besides these sociodemographic factors, personality attributes can influence the self-efficacy of consuming tobacco. ${ }^{9}{ }^{10}$ Self-efficacy-the perceived ability to execute any behaviour-regulates motivation, direct control over behavioural patterns and the ability to cope with stressors, ${ }^{11}$ thus affecting tobacco consumption.

Furthermore, the community's norm related to tobacco use can reciprocally influence an individual's behaviour. ${ }^{12}{ }^{13}$ It is possible that conformity with the collective social norm related to tobacco consumptionalso known as the peer influence ${ }^{14}$-affects an individual's behaviour toward tobacco use. ${ }^{1516}$ However, the diffusion of this influence requires exposure of an individual to interpersonal or social cues. Depending on the characteristics of social networks and relationships-defined as the social capital ${ }^{17}$ - the social norm around tobacco use may also differ. ${ }^{18} 19$

In the context of UP, tobacco consumption is historically and culturally normalised. ${ }^{20}$ However, to date, there is no evidence on how social capital and/or peer influence affect an individual's tobacco consumption in northern India, where one in every three adults currently using any form of tobacco product. ${ }^{21} 22$ Though current population-based surveys on tobacco-such as Global Adult Tobacco Survey (GATS), ${ }^{23}$ Global Youth Tobacco Survey $^{24}$ or WHO's STEPwise approach to surveillance ${ }^{25}$ collect some information on peer influence, no specific data is collected on social capital's role on tobacco use.
Addressing these existing research gaps, this study aimed to explore social capital and peer influence as critical determinants of tobacco use among household heads in rural UP, India.

\section{Social capital and peer influence as determinants of tobacco consumption in rural UP, India}

To conceptualise social capital and peer influence as determinants of tobacco consumption and empirically investigate their influence on tobacco use, this study adopted a conceptual framework from social cognitive theory (SCT) and social capital theory (figure 1). Proposed by Albert Bandura, SCT explains the process of acquiring and sustaining any behavioural pattern based on a triadic relationship among a person's behaviour, his/her personality attributes and the social environment. ${ }^{26}$ While deconstructing these relationships, Bandura ${ }^{11}$ explored four critical concepts: observational learning, self-efficacy, outcome expectations and reciprocal causation. In our study, we have theorised the first two concepts of SCT to explore the role of peer influence and social capital on tobacco consumption.

The causal relationship between health behaviour and the social environment is well established.$^{26}{ }^{27}$ Social environment affects individual behaviour by '...shaping norms, enforcing social control, enabling or not enabling people to participate in particular behaviors'. ${ }^{18}$ Above and beyond the addictive nature of tobacco, peer influence within a community, where tobacco use is normalised, may model an individual's tobacco consumption through observational learning. ${ }^{28-30}$

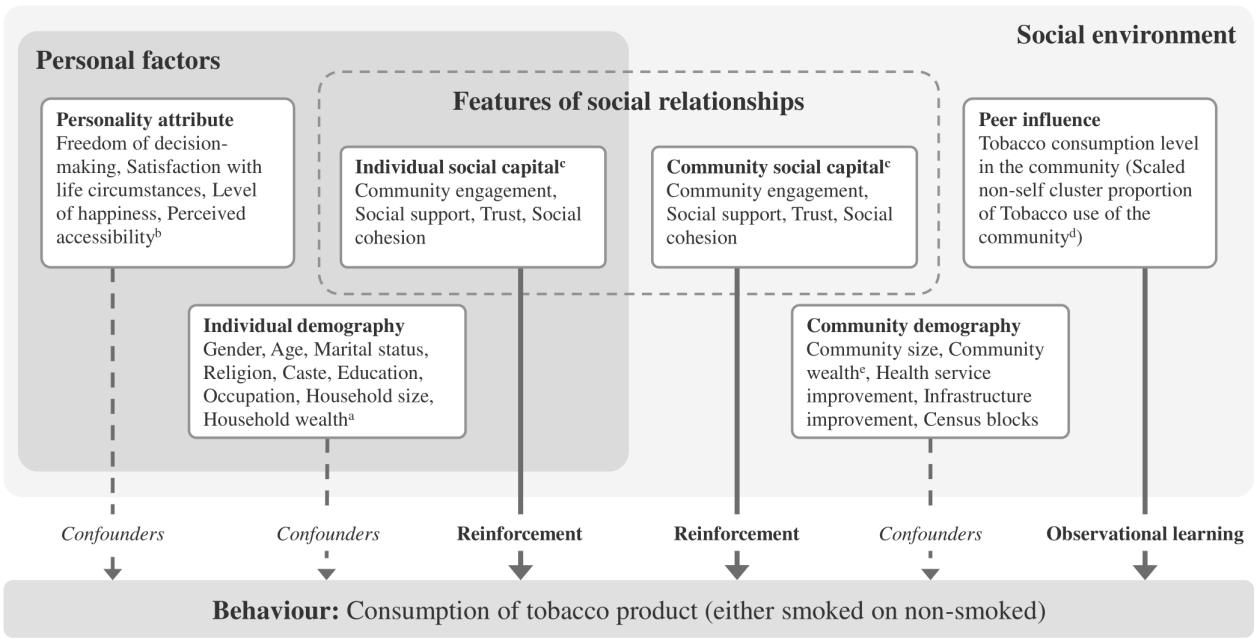

Figure 1 Conceptual framework derived from social cognitive theory to examine the role of social capital and peer influence

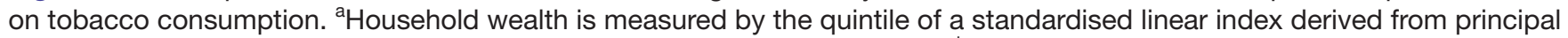
component analysis using 27 binary indicators related to household's asset. 'Perceived accessibility was measured by household head's perception of improvement of village infrastructure service (eg, roads, electricity and water supply). 'Social capital was measured by Shortened Adapted Social Capital Assessment Tool in India (SASCAT-I). Standardised factor scores as the measure of individual and community level social capital were generated by multilevel confirmatory factor analysis.

'Scaled 'no-self' cluster proportion of tobacco use was generated by calculating the proportion of the household heads in the community (primary sampling unit (PSU)) who consumed tobacco while excluding the respondent both from the numerator and denominator, and then multiplying the proportion by 10 . One unit increase in this scaled indicator represents a $10 \%$ increase in non-self cluster proportion of tobacco use. ${ }^{e}$ Community wealth is measured by the PSU average of standardised asset index of the households. 
This study also considered social capital as an intersectional determinant between an individual and his/ her social environment. It signifies the characteristics of an individual's or a group's social network and relationship. ${ }^{172}$ Social capital is a multidimensional and multilevel concept that can act as both individual and community level constructs, and acknowledged as a crosscutting social determinant of health. ${ }^{21} 2231$ It is classified into structural and cognitive components. ${ }^{32}$ Structural social capital signified the associational link between individuals and groups. It is represented by engagement with social organisation and exchange of social support. Structural social capital plays a critical role by directly reinforcing an individual's behaviour. This can happen when a person tries to access informational or instrumental resources through his or her social network. ${ }^{33} 34$ It was shown in a cluster randomised controlled trial in Dutch schools where the social network was used to alter smoking behaviour. ${ }^{35}$

On the other hand, the cognitive component of social capital embodies more subjective constructs-such as trust, social cohesion, reciprocity. ${ }^{22}$ A person with high cognitive social capital often tries to align himself or herself with the existing social norms, leading to either promotive or coercive health-related practices. ${ }^{36}$ A study from southern Sweden that has shown a higher level of individual trust was negatively correlated with tobacco use. ${ }^{37}$ Similar findings were reported by Brown and colleagues ${ }^{38}$ where higher community social capital related to the religious group has a significant and negative correlation with the number of cigarettes consumed by smokers.

Based on the conceptual framework (figure 1), we evaluated two potential pathways through which social capital and peer influence may affect individual tobacco consumption. First, peer influence could be positively associated with tobacco consumption because the high level of tobacco use in the community may provide enabling social cues (observational learning) to other members believing tobacco use a social norm. Second, individual and community level social capital might be positively associated with tobacco consumption due to the reinforcing effect of the social relations on selfefficacy. While exploring these two pathways, we considered personality attributes, individual and community level demographics and socioeconomic variables as confounders in the analysis.

\section{METHODS}

\section{Study design and population}

This study was embedded within the baseline evaluation of Project Samuday-a multisectoral rural development initiative in UP, India. ${ }^{39} 40$ The study area, Hardoi and Sitapur districts, is a rural region, and the health and human development indicators of these areas are below the state average. ${ }^{41}$ A community-level cross-sectional household survey was conducted from June to August 2017 in the six census blocks of Hardoi and Sitapur. Using stratified random sampling, 17-18 households were selected from each of the 346 primary sampling units (PSUs), also known as gram panchayats (GPs). Due to the high level of illiteracy in the study area $(61 \%),{ }^{42}$ obtaining written informed consent was not feasible. Instead, oral informed consent was received from the participants following the standard research practice in India. ${ }^{43}$ In total, 6218 households were surveyed with a response rate of $>99 \%$. The details of the survey design, sampling procedure and strategies to ensure sample attrition were reported in the online supplementary materials of this paper. During the survey, trained data collectors interviewed 6218 household heads ( $\geq 18$ years) using a multi-topic questionnaire. Information on tobacco use, along with demographic, socioeconomic, psychosocial factors, and social capital were collected using a computer-assisted personal interviewing system.

\section{Measurement and variables}

The dependent variable, tobacco consumption, was measured by asking each household heads, 'Do you currently use any tobacco products?' and the response categories included cigarettes, bidis or hookah, chewing tobacco or gutkha, and multiple responses were possible.

Covariates of this study were operationalised and classified as the peer influence of tobacco use, social capital measures, personality attributes, individual and community level demographics and socioeconomic factors. Detailed descriptions of the covariates are provided in the online supplementary materials of this paper.

\section{Peer influence of tobacco use}

Aggregating individual data at the PSU level, the measure of peer influence was constructed by calculating the "nonself' cluster proportion of tobacco use among household heads to understand the endogenous social effect. ${ }^{44-46}$ This indicator was calculated as-the number of other household heads (excluding the respondent) residing in the community who also consumed tobacco, divided by the total number of other household heads in the same community (see online supplementary materials for details of the calculation). To make the indicator more interpretable, we scaled it by multiplying the indicator by 10.

\section{Social capital}

We used the Shortened Adapted Social Capital Assessment Tool in India (SASCAT-I) to measure individual social capital, ${ }^{47}$ with 13 questions exploring-group membership (2 questions), collective action (2 questions), social support (3 questions), trust (3 questions) and social cohesion (3 questions). Multilevel confirmatory factor analysis (MCFA) was used to generate standardised factor scores of social capital measures. At both individual and community levels, four unique social capital factors emerged from MCFA, which were defined as community engagement, social support, trust and social cohesion. 


\section{Personality attributes}

To account for the unique personality of each household head, we included freedom of decision-making, satisfaction with life circumstances, level of happiness and perceived accessibility as categorical explanatory variables. $^{48-51}$ Detailed descriptions of how each of these variables were constructed are provided in the online supplementary materials of this paper.

\section{Individual demography}

To account for the individual characteristics, we considered self-reported gender, age, marital status, educational attainment, occupation, religion, caste, household size as demographic covariates. ${ }^{6253}$ There were eight observations where self-reported age was missing, which is less than $1 \%$ of the data. These missing values were replaced by the mean age of the participants for the ease of the analysis. Furthermore, age was stratified into five categories, such as $\leq 30$ years, 31-40 years, 41-50 years, 51-60 years and $>60$ years. A household was considered 'large' if more than five members were living in the house and 'small' otherwise. Household wealth was measured as a linear index generated using PCA of 27 binary indicators related to asset ownership. ${ }^{54}$ Each household was assigned to a wealth quintile based on the asset index considering quintile five as wealthiest.

\section{Community demography}

Community wealth was derived by averaging the standardised asset index scores of all households within a PSU. Any recent improvement of the community's health service and infrastructure (eg, roads, electricity and water supply) were measured by averaging individual household head's response. Also, each community was categorised into small, medium and large based on the population of GP reported in the 2011 Census of India. ${ }^{55}$ Lastly, we included the census blocks to account for the geographic variability in the analysis.

\section{Statistical analyses}

Data management and analysis were performed using Stata 15.1. ${ }^{56}$ Mplus 8.1 was used to perform the MCFA and generate individual and community level factor scores of social capital. ${ }^{57}$ As a descriptive analysis, first, the pattern of tobacco product use was reported. Next, we assessed the explanatory power of each covariate by calculating unadjusted odds ratios (ORs) using generalised estimating equations (GEEs) with robust standard errors (SEs) (Huber/White/sandwich estimator). Lastly, multiple GEE logistic regressions were implemented to estimate the adjusted ORs by simultaneously incorporating those covariates, which represented a p-value $\leq 0.2$ in the unadjusted models. ${ }^{58}$ Wald tests were performed after running the regression models to estimate the overall significance of categorical variables. Multicollinearity of the explanatory variables was assessed using the variance inflation factor. The goodness of fit of the models was evaluated using the Hosmer-Lemeshow goodness-of-fit test.

\section{Patient and public involvement}

No patients and the public were involved in the design or planning of the study.

\section{RESULTS}

The detailed description of the sample, including the respondents' tobacco consumption pattern, is provided in table 1.

Among all the household heads, $62 \%(n=3884)$ reported using any type of tobacco products, $31 \%(n=1913)$ were smoker and $43 \%(n=2669)$ chewed tobacco products. On average, $71 \%(\mathrm{n}=3753)$ men and $14 \%(\mathrm{n}=131)$ women household heads consumed any type of tobacco products. Across product types, a significantly higher proportion of men used tobacco, compared with woman household heads $(p<0.01)$. Due to the noticeable difference across gender-moving forward-a gender-stratified descriptive and regression analysis was implemented. Among the respondents, a higher proportion of the women household heads were illiterate and belonged to lower wealth quintiles. While the average standardised factor scores of community engagement and social support were significantly higher among men compared with women $(p<0.05)$, women had a significantly higher score of Trust $(\mathrm{p}<0.05)$. However, considering only those participant who consumed tobacco products (table 2), the mean standardised factor scores of all four individual social capital covariates were higher among women household heads compared with men. However, none of them are statistically significant (see online supplementary materials for details). Table 2 presents the distribution of household heads who consumed tobacco across the covariates disaggregated by gender. At the community level, the average peer influence of tobacco use was $64 \%$, which ranged from $12.6 \%$ to $100 \%$. Community-level social capital constructs presented minimal correlation with the measure of peer influence. (Data are not shown. See online supplementary materials for details.)

Tables 3 and 4 present the results of the bivariate and multivariate GEE logistic regression models for men and women accordingly. When accounting for all covariates, peer influence presented a significantly positive association with tobacco consumption only for men. If the peer influence in the community increased by $10 \%$, the likelihood of a man would consume tobacco increased by $10 \%$ points (adjusted OR $(\mathrm{AOR})=1.10,95 \% \mathrm{CI}=1.05$ to 1.16 , $\mathrm{p}<0.01)$. Among other covariates, age, educational attainment and level of happiness of men presented a negative and almost dose-response relationship pattern with tobacco use. On the other hand, with higher perceived accessibility, the odds of a man's tobacco consumption were significantly increased.

While we did not observe any association between peer influence on woman's tobacco consumption behaviour, only one social capital construct-individual-level community engagement—was significantly associated with woman household head's tobacco use. Adjusting 
Table 1 Respondent characteristics disaggregated by gender in rural Uttar Pradesh, India (N=6218)

\section{Gender of the respondent}



Smoking tobacco products

$\begin{array}{llllrrrrrrr}\text { No } & 3430 & 64.57 & 79.67 & 875 & 96.58 & 20.33 & 4305 & 69.23 & 100.00 \\ \text { Yes } & 1882 & 35.43 & 98.38 & 31 & 3.42 & 1.62 & 1913 & 30.77 & 100.00 \\ \text { Chewing tobacco products } & & & & & & & & \\ \text { No } & 2748 & 51.73 & 77.43 & 801 & 88.41 & 22.57 & 3549 & 57.08 & 100.00 \\ \text { Yes } & 2564 & 48.27 & 96.07 & 105 & 11.59 & 3.93 & 2669 & 42.92 & 100.00 \\ \text { Using any tobacco product } & & & & & & & & \\ \text { No } & 1559 & 29.35 & 66.80 & 775 & 85.54 & 33.20 & 2334 & 37.54 & 100.00 \\ \text { Yes } & 3753 & 70.65 & 96.63 & 131 & 14.46 & 3.37 & 3884 & 62.46 & 100.00\end{array}$

Age categories*




Table 1 Continued

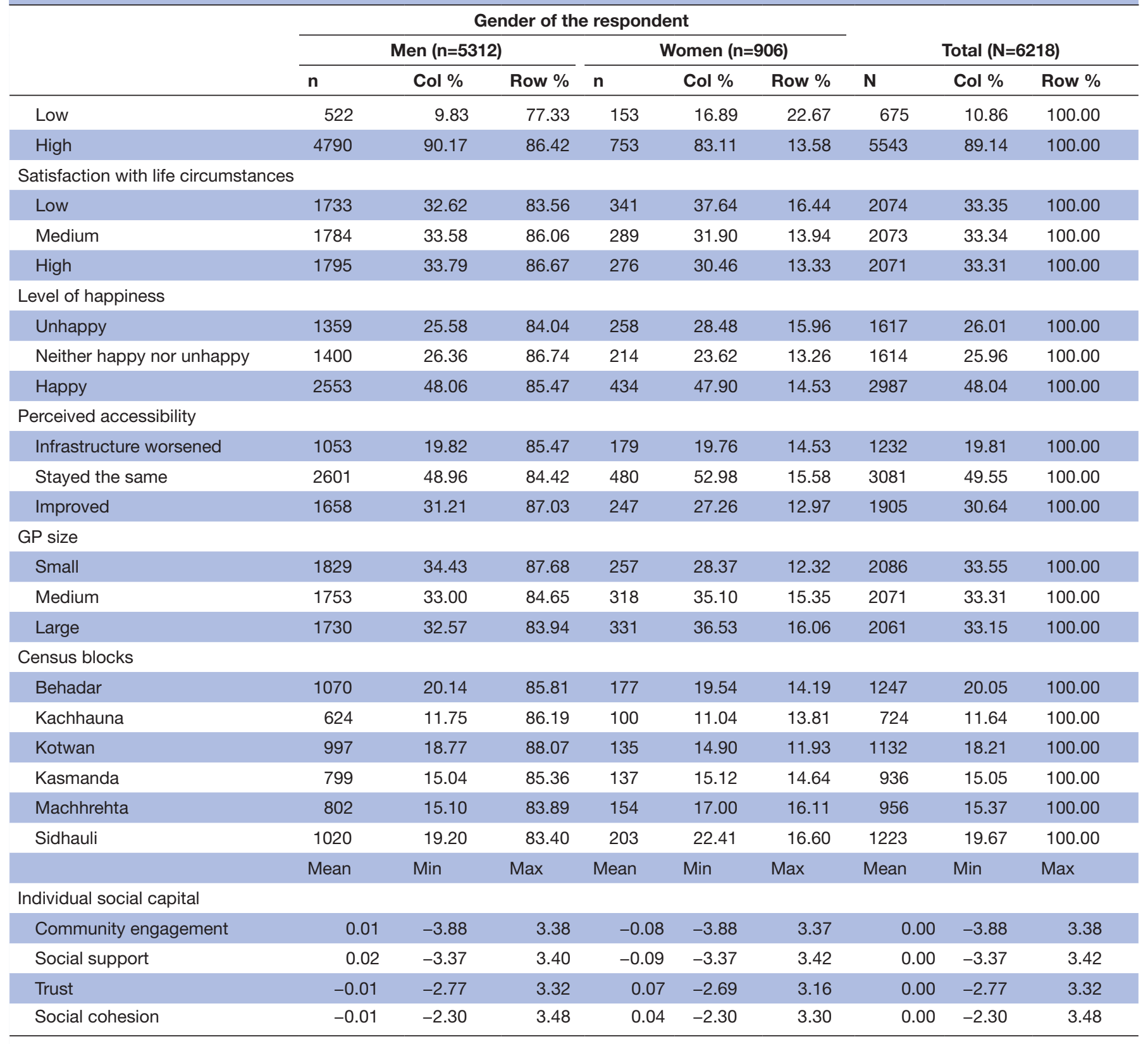

*Variable age has eight missing values.

max, maximum; min, minimum; OBC, other backward caste; ST/SC, scheduled caste and scheduled tribe.

for confounders, 1 standard deviation (SD) increase in the standardised factor score of individual community engagement was associated with a $33 \%$ increase in the odds of tobacco consumption for a woman household head ( $\mathrm{AOR}=1.33,95 \% \mathrm{CI}=1.07$ to $1.66, \mathrm{p}=0.01$ ). Besides, woman household head's tobacco consumption was significantly associated with their religion, social caste and the size of the household.

\section{DISCUSSION}

Using the data from a multi-topic survey among rural household heads, we explored the relationships of peer influence and social capital with tobacco consumption. We found that peer influence was permissive for tobacco consumption; however, this association was only observed in men. On the other hand, a higher level of community engagement by a woman presented a significant and positive association with her tobacco consumption status.

We have found that the peer influence of the community 'DOES' affect a man's tobacco consumption behaviour beyond his personal preference. Thus, our theorised pathway of observational learning from the social environment was partially supported by the result. The social environment conveys norms and culture, 
Table 2 Characteristics of the respondent who consumed tobacco disaggregated by gender in rural Uttar Pradesh, India $(\mathrm{N}=3884)$

\begin{tabular}{|c|c|c|c|c|c|c|c|c|c|}
\hline & \multicolumn{6}{|c|}{ Gender of the respondents who consumed tobacco products } & \multirow[b]{3}{*}{$\mathbf{N}$} & \multirow{2}{*}{\multicolumn{2}{|c|}{ Total $(\mathrm{N}=3884)$}} \\
\hline & \multicolumn{3}{|c|}{ Men $(n=3753)$} & \multicolumn{3}{|c|}{ Women $(n=131)$} & & & \\
\hline & $\mathbf{n}$ & Col \% & Row \% & $\mathbf{n}$ & Col \% & Row \% & & Col \% & Row \% \\
\hline$\leq 30$ years & 667 & 17.80 & 96.95 & 21 & 16.03 & 3.05 & 688 & 17.74 & 100.00 \\
\hline $31-40$ years & 1044 & 27.86 & 97.30 & 29 & 22.14 & 2.70 & 1073 & 27.67 & 100.00 \\
\hline$>60$ years & 445 & 11.88 & 95.29 & 22 & 16.79 & 4.71 & 467 & 12.04 & 100.00 \\
\hline \multicolumn{10}{|l|}{ Marital status } \\
\hline Never married/not stated & 100 & 2.66 & 98.04 & 2 & 1.53 & 1.96 & 102 & 2.63 & 100.00 \\
\hline Married & 3462 & 92.25 & 97.52 & 88 & 67.18 & 2.48 & 3550 & 91.40 & 100.00 \\
\hline \multicolumn{10}{|l|}{ Caste } \\
\hline General & 583 & 15.53 & 94.64 & 33 & 25.19 & 5.36 & 616 & 15.86 & 100.00 \\
\hline ST/SC & 1831 & 48.79 & 97.50 & 47 & 35.88 & 2.50 & 1878 & 48.35 & 100.00 \\
\hline $\mathrm{OBC}$ & 1339 & 35.68 & 96.33 & 51 & 38.93 & 3.67 & 1390 & 35.79 & 100.00 \\
\hline \multicolumn{10}{|l|}{ Education } \\
\hline Illiterate & 1375 & 36.64 & 94.11 & 86 & 65.65 & 5.89 & 1461 & 37.62 & 100.00 \\
\hline Up to primary & 1028 & 27.39 & 97.72 & 24 & 18.32 & 2.28 & 1052 & 27.09 & 100.00 \\
\hline Up to secondary & 1069 & 28.48 & 98.43 & 17 & 12.98 & 1.57 & 1086 & 27.96 & 100.00 \\
\hline Above secondary & 281 & 7.49 & 98.60 & 4 & 3.05 & 1.40 & 285 & 7.34 & 100.00 \\
\hline Unemployed & 139 & 3.70 & 93.29 & 10 & 7.63 & 6.71 & 149 & 3.84 & 100.00 \\
\hline \multicolumn{10}{|l|}{ Household wealth } \\
\hline Quintile 1 & 746 & 19.88 & 94.67 & 42 & 32.06 & 5.33 & 788 & 20.29 & 100.00 \\
\hline Quintile 2 & 788 & 21.00 & 96.92 & 25 & 19.08 & 3.08 & 813 & 20.93 & 100.00 \\
\hline Quintile 3 & 794 & 21.16 & 97.66 & 19 & 14.50 & 2.34 & 813 & 20.93 & 100.00 \\
\hline Quintile 4 & 750 & 19.98 & 97.78 & 17 & 12.98 & 2.22 & 767 & 19.75 & 100.00 \\
\hline Quintile 5 & 675 & 17.99 & 96.02 & 28 & 21.37 & 3.98 & 703 & 18.10 & 100.00 \\
\hline \multicolumn{10}{|l|}{ Freedom decision-making } \\
\hline Low & 358 & 9.54 & 93.47 & 25 & 19.08 & 6.53 & 383 & 9.86 & 100.00 \\
\hline High & 3395 & 90.46 & 96.97 & 106 & 80.92 & 3.03 & 3501 & 90.14 & 100.00 \\
\hline \multicolumn{10}{|l|}{ Satisfaction with living condition } \\
\hline Low & 1260 & 33.57 & 95.67 & 57 & 43.51 & 4.33 & 1317 & 33.91 & 100.00 \\
\hline Medium & 1285 & 34.24 & 97.42 & 34 & 25.95 & 2.58 & 1319 & 33.96 & 100.00 \\
\hline High & 1208 & 32.19 & 96.79 & 40 & 30.53 & 3.21 & 1248 & 32.13 & 100.00 \\
\hline \multicolumn{10}{|l|}{ Level of happiness } \\
\hline Unhappy & 1029 & 27.42 & 96.80 & 34 & 25.95 & 3.20 & 1063 & 27.37 & 100.00 \\
\hline Neither happy nor unhappy & 976 & 26.01 & 96.92 & 31 & 23.66 & 3.08 & 1007 & 25.93 & 100.00 \\
\hline Happy & 1748 & 46.58 & 96.36 & 66 & 50.38 & 3.64 & 1814 & 46.70 & 100.00 \\
\hline
\end{tabular}


Table 2 Continued

\begin{tabular}{|c|c|c|c|c|c|c|c|c|c|}
\hline & \multicolumn{6}{|c|}{ Gender of the respondents who consumed tobacco products } & & & \\
\hline & \multicolumn{3}{|c|}{ Men $(n=3753)$} & \multicolumn{3}{|c|}{ Women $(n=131)$} & \multicolumn{3}{|c|}{ Total $(\mathrm{N}=\mathbf{3 8 8 4})$} \\
\hline & $\mathbf{n}$ & Col \% & Row \% & $\mathbf{n}$ & Col \% & Row \% & $\mathbf{N}$ & Col \% & Row \% \\
\hline Infrastructure worsened & 666 & 17.75 & 95.97 & 28 & 21.37 & 4.03 & 694 & 17.87 & 100.00 \\
\hline Stayed the same & 1886 & 50.25 & 96.67 & 65 & 49.62 & 3.33 & 1951 & 50.23 & 100.00 \\
\hline Small & 1311 & 34.93 & 97.47 & 34 & 25.95 & 2.53 & 1345 & 34.63 & 100.00 \\
\hline Medium & 1215 & 32.37 & 95.52 & 57 & 43.51 & 4.48 & 1272 & 32.75 & 100.00 \\
\hline Large & 1227 & 32.69 & 96.84 & 40 & 30.53 & 3.16 & 1267 & 32.62 & 100.00 \\
\hline \multicolumn{10}{|l|}{ Census blocks } \\
\hline Machhrehta & 539 & 14.36 & 95.57 & 25 & 19.08 & 4.43 & 564 & 14.52 & 100.00 \\
\hline \multirow[t]{2}{*}{ Sidhauli } & 710 & 18.92 & 94.92 & 38 & 29.01 & 5.08 & 748 & 19.26 & 100.00 \\
\hline & Mean & Min & Max & Mean & Min & Max & Mean & Min & Max \\
\hline \multicolumn{10}{|l|}{ Individual social capital } \\
\hline Community engagement & 0.01 & -3.88 & 3.38 & 0.11 & -2.84 & 3.15 & 0.01 & -3.88 & 3.38 \\
\hline Social support & 0.01 & -3.37 & 3.40 & 0.11 & -2.44 & 3.42 & 0.01 & -3.37 & 3.42 \\
\hline Trust & -0.01 & -2.76 & 3.32 & 0.10 & -2.38 & 3.01 & -0.01 & -2.76 & 3.32 \\
\hline Social cohesion & -0.01 & -2.30 & 3.48 & 0.05 & -2.08 & 3.10 & -0.01 & -2.30 & 3.48 \\
\hline
\end{tabular}

*Variable age has six missing values among the participants who used tobacco products.

max, maximum; min, minimum; OBC, other backward caste; ST/SC, scheduled caste and scheduled tribe.

which affects our behaviour during our everyday life. While the evidence is limited in the Indian context, previous studies substantiated the impact of peer influence-also known as the social modelling effect-on tobacco use and substance abuse. ${ }^{28-30} 59$ The contents of the social norm have intrinsic value, which can determine how it affects health-either positively or negatively. Living in a community where-on average-two-thirds of the other household heads engaged in tobacco consumption may indicate it as peer behaviour, and may compel individuals to behave similarly to consume tobacco. ${ }^{60} \mathrm{In}$ the context of rural northern India, the social circle of men is generally inclusive of friends, coworkers and advisors beyond the boundary of their immediate family. On the other hand, women were more likely to be associated with their relatives, kins and female neighbours. ${ }^{61-63}$ Men are likely to be more exposed to the peer influence that emerged from the tobacco consumption habit of other men compared with the woman head of the household.

What if a woman can expand her social circle and actively participate in the community-will it affect their tobacco consumption behaviour? That was the premise of the second pathway of our conceptual framework related to social capital. We found community engagement of individual woman household head was associated with tobacco use. Lindström suggested formal or informal social interactions in the community often promote harmful health-related norms. ${ }^{18}$ Previous literature also indicates that higher community participation and social interaction might encourage tobacco consumption and smoking behaviour. ${ }^{64} 65$ It is very much possible that breaking out of their immediate social circle exposes a woman to the peer influence of tobacco use which in terms affects her behaviour.

One of the null findings of our study was - no observed association of individual or community-level social support with tobacco consumption behaviour of the household heads. Several randomised controlled trials and observational studies were conducted to understand the attribution of social support on smoking cessation. ${ }^{66-70}$ While there was no consensus among these studies, mostly a positive association was hypothesised between social support and cessation of tobacco use. Westmaas and colleagues explored several of these studies to develop a theoretical framework explaining how social support affects the motivation behind and the success of smoking cessation. ${ }^{71}$ According to them, beyond the structural support-such as social integration and engagement with the support network-it is critical to have functional support to help individuals quitting tobacco. Functional social support may come in many forms, including empathy, emotional support and assistance to cope with 
Table 3 Bivariate and multivariate ORs of tobacco use among male household heads estimated by generalised estimating equation logistic regression model in rural Uttar Pradesh, India $(n=5312)$




Table 3 Continued

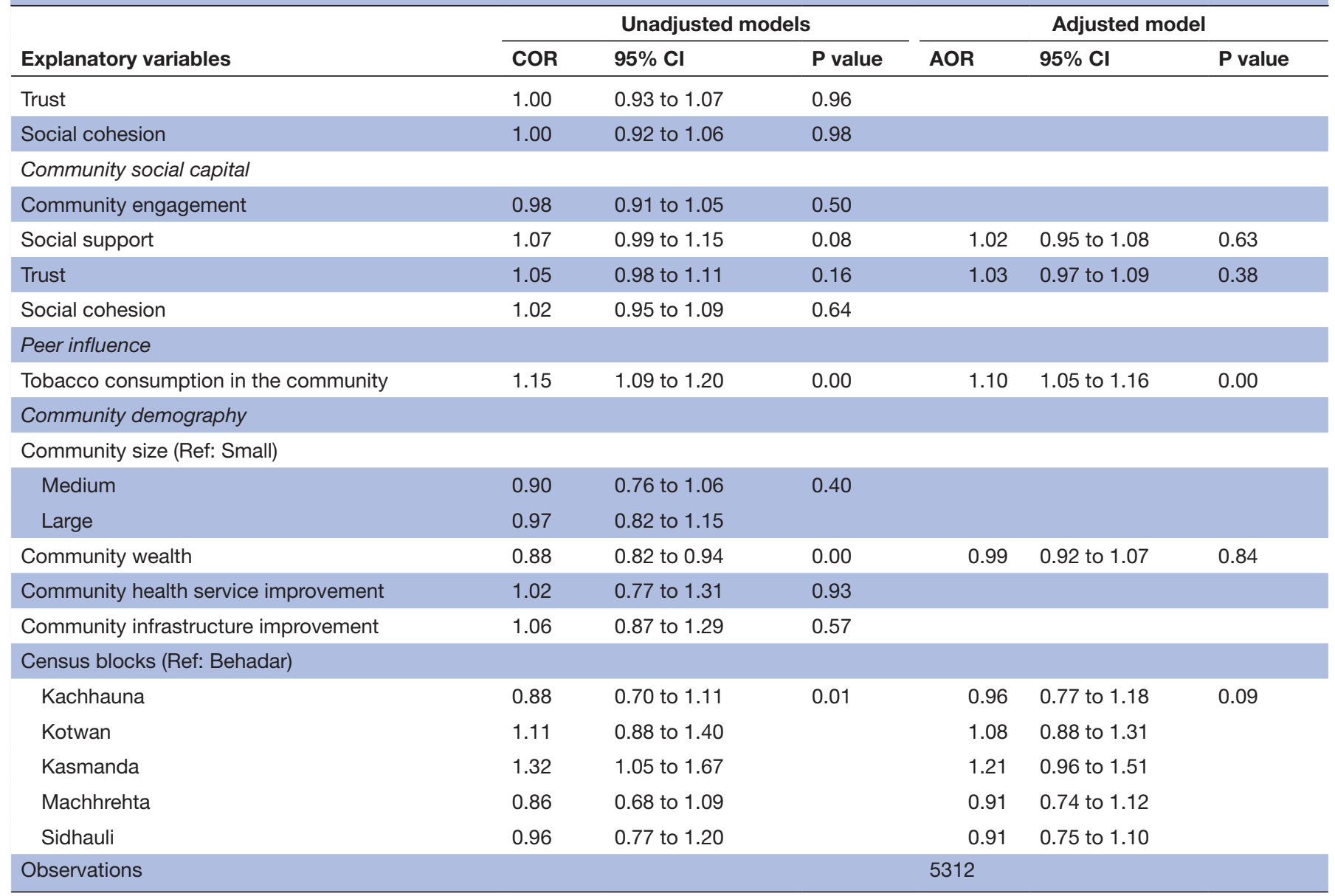

*The missing values of age $(n=7)$ were replaced by the average age of the participants.

AOR, adjusted OR; COR, crude or unadjusted OR; OBC, other backward caste; Ref, reference; ST/SC, scheduled caste and scheduled tribe.

withdrawal effects. As tobacco use is not considered as a deviant social behaviour-instead accepted as a social norm in rural $\mathrm{UP}^{20}$ - and with very few interventions to denormalise tobacco use culture, observing no association between social support and tobacco consumption was expected.

While the association was observed only among men, it is essential to acknowledge the protective effect of education observed in our study, which is consistent with the current literature. $^{72}{ }^{73}$ Besides, accessibility was found to be a positively associated factor among men-but not among women, which may indicate their restricted social mobility. ${ }^{62}$ The result also showed that religion and caste significantly correlated with tobacco consumption, particularly among women. While women are inherently vulnerable in the patriarchal society of northern India, it appeared that not belonging to the religious majority could make them more susceptible to tobacco exposure.

\section{Strengths and limitations of the study}

This is the first study to integrate two established theoretical frameworks of social science, SCT and social capital theory, in the context of tobacco use, which makes our study theoretically robust. This study was also able to include a large number of covariates beyond respondent's individual demographic and socioeconomic characteristics by including several personality attributes, social capital measures and contextual characteristics of the communities while using a large population-based sample of the household heads in rural UP.

The tobacco use status of the respondents was measured by self-reported questions in our study. Though this is the standard practice of GATS and other substance use research, ${ }^{223}$ self-reported behaviour and actual tobacco consumption pattern can be different. Due to the limitation of data, we were unable to account for outcome expectations-the knowledge of the positive or negative consequences of tobacco use. ${ }^{11}$ We believe that incorporating education as a covariate would account for outcome expectations. ${ }^{53} 74$ Additionally, causality or temporal association cannot be established with crosssectional data. This is linked with another essential tenet of SCT-reciprocal causation (the bidirectional influence of individual behaviour and social environment). ${ }^{75}$ Lastly, some known predictors of tobacco use such as substance abuse, existing comorbidity (eg, diabetes, hypertension) and psychological stressors (eg, 
Table 4 Bivariate and multivariate ORs of tobacco use among women household heads estimated by generalised estimating equation logistic regression model in rural Uttar Pradesh, India $(n=906)$




Table 4 Continued

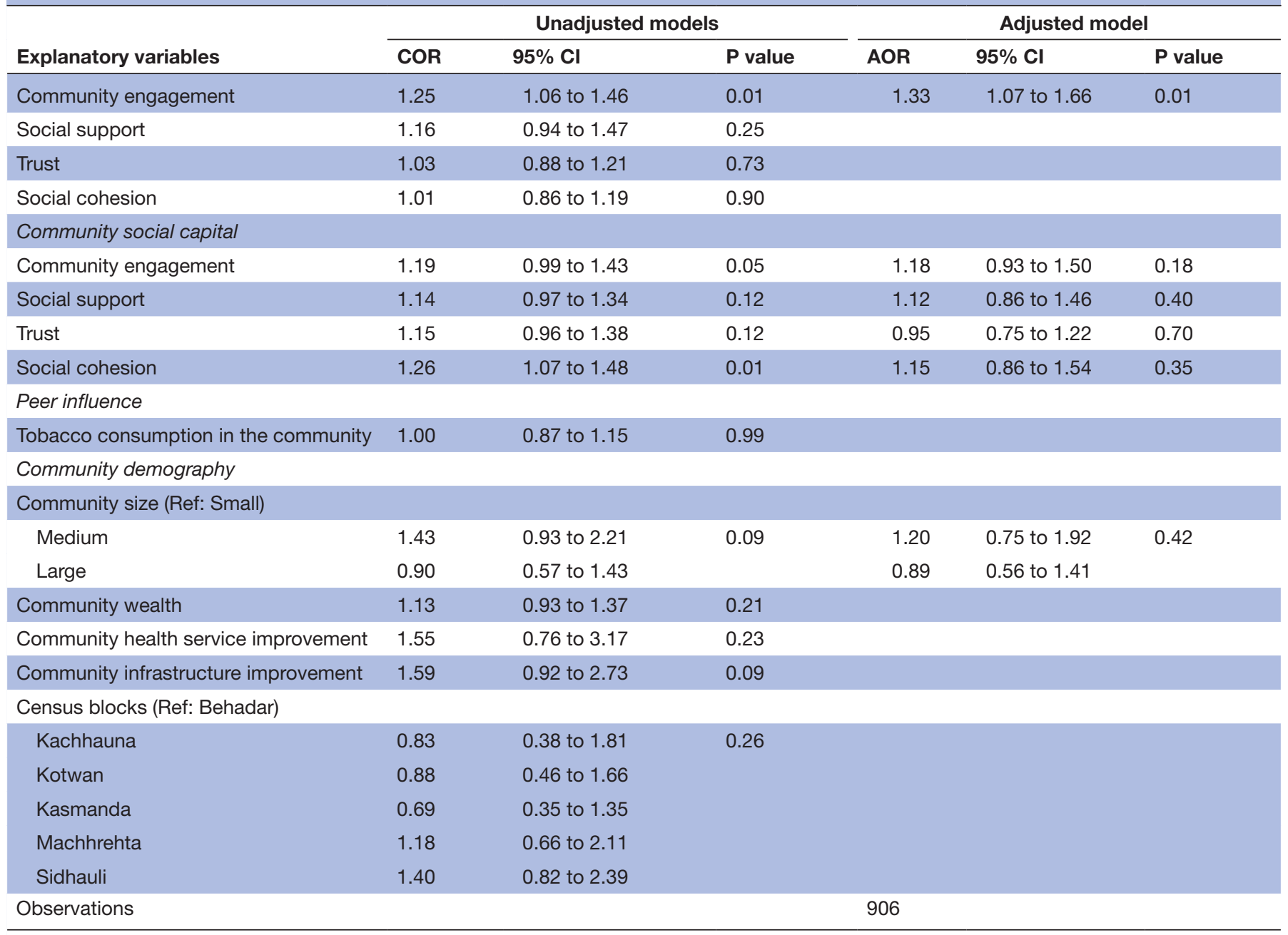

${ }^{*}$ The missing values of age $(n=1)$ were replaced by the average age of the participants.

AOR, adjusted OR; COR, crude or unadjusted OR; OBC, other backward caste; Ref, reference; ST/SC, scheduled caste and scheduled tribe.

depression, anxiety) were not included in the analysis due to limited data availability.

\section{Policy implications}

Despite these limitations, we believe the study findings are still generalisable to the broader rural population of northern India, as the underlying relationship between tobacco use, social capital and peer influence can be consistent. Moreover, exploring the household head's tobacco consumption is extremely critical as they are the decision-maker in the house. Their behaviour can impact the health of the entire household by secondhand and thirdhand smoking ${ }^{76}$ and by normalising this harmful behaviour to other members of the household providing some enabling social cues. ${ }^{60}$

Thus, changing the social norm around tobacco use is our policy recommendation. In India, the majority of tobacco control policies focus on an individual's behaviour. These include pack warnings, smoke-free zones, sin taxes on tobacco products, behavioural change communication using television/radio campaign and smoking cessation programme in a limited capacity. ${ }^{78}$ To support these existing interventions, the protective effect of education can be leveraged. Reorienting and adapting the traditional anti-tobacco behavioural change communication strategies into online and social media platforms can be an innovative strategy. ${ }^{79}$ One such intervention, mCessation-a mobile phone-based anti-smoking text message service-has shown some promising results in recent years. ${ }^{80}$ Incorporation of the information regarding the National Tobacco Quitline and mCessation programme in the pack warnings must be effectively implemented for both smoked and smokeless tobacco products. ${ }^{81}$

As our result suggested, tobacco use in rural UP may have an active social and cultural component. Daily social interaction among individuals and groups is often accompanied by the use of hookah, bidi or other forms of tobacco. ${ }^{82}$ By recognising the nuance of the culture, the denormalisation of smoked and smokeless tobacco in the community by a community-based participatory approach can synergise the current tobacco control strategy in India. ${ }^{83}$ Community-based participatory research (CBPR) approach showed improved 
acceptability of tobacco control measures by changing social norms in other places. ${ }^{85}{ }^{86}$ Here, engaging the rural community will play a catalytic role. One approach can be formalising tobacco control peer-support groups within the existing Village Health Sanitation and Nutrition Committees (VHSNCs), including village leaders, accredited social health activists (ASHA) and health providers. ${ }^{87}$ Leveraging VHSNCs will be a cost-effective and culturally acceptable strategy to complement the tobacco control activities led by UP's State and District Tobacco Control Cells ${ }^{88}$ Furthermore, systematic evaluation and scale-up of such CBPR-based tobacco control intervention can strengthen the Ayushman Bharat programme, which expanded the scope of community-level primary care by including NCD prevention and treatment. ${ }^{89}$

Our study was also able to provide a glimpse of the effect of gender dynamics on tobacco use. In India, active participation of women in community activities and decision-making are advocated by national and state-level governments. ${ }^{90} 91$ Non-government organisations, academic and research institutions are also striving to organise bottom-up movements to ensure gender equity in Indian society. ${ }^{92}$ While gender mainstreaming is a critical egalitarian agenda that needs to be pursued without interruption-we also need to acknowledgethis process will expose women to the broader social sphere, which effect is not necessarily been understood by researchers. Thus, more research is needed to understand the influence of gender mainstreaming on smoked and smokeless tobacco-related norms in conjunction with tobacco-related disparities across religious, caste and class hierarchies. Moreover, the design and implementation of any CBPR-based tobacco control intervention need to account for these sociocultural dynamics.

\section{CONCLUSION}

Independently social capital and peer influence act as determinants of tobacco use in rural UP, though not simultaneously for men and women. While the peer influence of tobacco use was permissive only for men, a woman who had higher community engagement was more susceptible to tobacco exposure. As India is moving through an epidemiological transition, ${ }^{93-95}$ tobacco control policies should address the current social context and the intersectoral nature of the tobacco industry and political sustainability. Recent evidence shows that some progress has been made against the tobacco epidemic, and momentum exists to continue these actions in this era of sustainable development goals. ${ }^{2}$ It is essential to ensure that national, state and local governments enforce the Cigarettes and Other Tobacco Products Act (COTPA). To confront the tobacco epidemic, a synergistic multisectoral, systemic and participatory approach should be adopted. As a potential solution, our study highlights some entry points for action to develop priority-setting tools and engage the community in the tobacco control strategy. We also recommend further exploration of the effect of social participation and gender on tobacco use. Furthermore, India should intensify its current tobacco control efforts with community-level participatory interventions to counter the peer influence of the use of smoked and smokeless tobacco.

\section{Author affiliations}

${ }^{1}$ Department of International Health, Johns Hopkins Bloomberg School of Public Health, Baltimore, Maryland, United States

${ }^{2}$ Department of Health, Behavior and Society, Johns Hopkins Bloomberg School of Public Health, Baltimore, Maryland, United States

${ }^{3}$ Institute for Global Tobacco Control (IGTC), Johns Hopkins Bloomberg School of Public Health, Baltimore, Maryland, United States

${ }^{4}$ Department of Population, Family and Reproductive Health, Johns Hopkins Bloomberg School of Public Health, Baltimore, Maryland, United States

${ }^{5}$ School of Public Policy, Central European University, Budapest, Hungary

\section{Twitter Md Zabir Hasan @ZabirHasan}

Acknowledgements We acknowledge the HCL Foundation, India, and Project Samuday for their instrumental support. We thank Dr Arindam Das, Dr Ranjan Kumar Prusty and Samresh Rai for their critical contribution during the data collection. We also thank our collaborating data collection agency Kantar Public and their team of researchers and data collectors. We also acknowledge the assistance of the Fogarty International Training Center (2D43TW007587-06), which supported the doctoral programme of the first author. Lastly, we thank our research participants for their time and support.

Contributors MZH, KDR, and SG conceptualised and designed of the study; MZH supervised the data collection and data management, and performed the statistical analysis; JEC, DB, CEK, KDR, AA, and SG contributed to the interpretation of the results; MZH led the manuscript writing and developed the first draft. All authors contributed to manuscript revision, and they have read and approved the submitted version.

Funding This work was supported by HCL Foundation, India (grant no: JHU 124005).

\section{Competing interests None declared.}

Patient and public involvement Patients and/or the public were not involved in the design, conduct, reporting or dissemination plans of this research.

Patient consent for publication Not required.

Ethics approval Ethical approval of the study was received from the Institutional Review Board Office of Johns Hopkins Bloomberg School of Public Health, Maryland, USA (IRB No: 00007469) and locally from the Centre for Media Studies, New Delhi, India (IRB No: IRB00006230).

Provenance and peer review Not commissioned; externally peer reviewed.

Data availability statement Data are available on reasonable request. The data supporting the result of this manuscript will be made available by the authors on request to any qualified researcher.

Open access This is an open access article distributed in accordance with the Creative Commons Attribution Non Commercial (CC BY-NC 4.0) license, which permits others to distribute, remix, adapt, build upon this work non-commercially, and license their derivative works on different terms, provided the original work is properly cited, appropriate credit is given, any changes made indicated, and the use is non-commercial. See: http://creativecommons.org/licenses/by-nc/4.0/.

\section{ORCID iDs}

Md Zabir Hasan http://orcid.org/0000-0001-8730-0054

Joanna E Cohen http://orcid.org/0000-0002-3869-3637

David Bishai http://orcid.org/0000-0003-0714-9062

Caitlin E Kennedy http://orcid.org/0000-0001-6820-063X

Krishna D Rao http://orcid.org/0000-0001-9347-3648

Akshay Ahuja http://orcid.org/0000-0002-1818-8721

Shivam Gupta http://orcid.org/0000-0003-1116-0459 


\section{REFERENCES}

1 Commar A, Prasad VK, Tursan d'Espaignet E, et al. WHO global report on trends in prevalence of tobacco smoking 2000-2025. 2 edn. Geneva, 2018.

2 Tata Institute of Social Sciences, Ministry of Health and Family Welfare, Government of India. Global adult tobacco survey: India 2016-17 report., 2017. Available: https://mohfw.gov.in/sites/default/ files/GlobaltobacoJune2018.pdf [Accessed 8 Nov 2018].

3 Government of India, World Health Organization. National action plan and monitoring framework for prevention and control of NCDS, 2013. Available: https://www.iccp-portal.org/system/files/plans/ India\%20-\%20National_Action_Plan_and_Monitoring_Framework Prevention_NCD_2013.pdf [Accessed 5 Jul 2018].

4 World Health Organization. WHO report on the global tobacco epidemic 2017: monitoring tobacco use and prevention policies, 2017.

5 Tata Institute of Social Sciences, Ministry of Health \& Family Welfare, Government of India. Global adult tobacco survey 2: Uttar Pradesh factsheet 2016-17, 2017. Available: https://tmc.gov.in/images/act/ Uttar\%20Pradesh\%20GATS-2\%20Factsheet\%20.pdf [Accessed 1 Dec 2019].

6 David A, Esson K, Perucic A-M. Tobacco use: equity and social determinants. In: Equity, social determinants and public health programmes, 2010: 199-218.

7 Sreeramareddy CT, Pradhan PM, Sin S, Prevalence SS. Prevalence, distribution, and social determinants of tobacco use in 30 subSaharan African countries. BMC Med 2014;12:243.

8 Hosseinpoor AR, Parker LA, Tursan d'Espaignet E, d'Espaignet $\mathrm{ET}$, et al. Social determinants of smoking in low- and middleincome countries: results from the world health survey. PLoS One 2011;6:e20331.

9 Singh-Manoux A. Psychosocial factors and public health. $J$ Epidemiol Community Health 2003;57:553-6.

10 Upton J, Factors P. Encyclopedia of behavioral medicine. New York, NY: Springer New York, 2013: 1580-1.

11 Bandura A. Health promotion from the perspective of social cognitive theory. Psychol Health 1998;13:623-49.

12 Hatzenbuehler ML, Wieringa NF, Keyes KM. Community-level determinants of tobacco use disparities in lesbian, gay, and bisexual youth: results from a population-based study. Arch Pediatr Adolesc Med 2011;165:527-32.

13 Fuemmeler B, Lee C-T, Ranby KW, et al. Individual- and communitylevel correlates of cigarette-smoking trajectories from age 13 to 32 in a U.S. population-based sample. Drug Alcohol Depend 2013;132:301-8.

14 Burger JM. Social influence, psychology of. In: International encyclopedia of the social \& behavioral sciences. Oxford: Pergamon, 2001: 14320-5.

15 Ahern J, Galea S, Hubbard A, et al. Neighborhood smoking norms modify the relation between collective efficacy and smoking behavior. Drug Alcohol Depend 2009;100:138-45.

16 Lozano P, Fleischer NL, Moore S, et al. Does neighborhood social cohesion modify the relationship between neighborhood social norms and smoking behaviors in Mexico? Health Place 2016;40:145-52.

17 Putnam RD. Bowling alone: America's declining social capital. In: Culture and politics. Springer, 2000: 223-34. http://link.springer.com/ chapter/

18 Lindström M. Social Capital and Health-Related Behaviors. In: Social capital and health. New York, NY: Springer New York, 2008: 215-38.

19 Lindström M. Social capital, social class and tobacco smoking. Expert Rev Pharmacoecon Outcomes Res 2008;8:81-9.

20 Mishra S, Mishra MB. Tobacco: its historical, cultural, oral, and periodontal health association. J Int Soc Prev Community Dent 2013;3:12-18.

21 Hasan MZ, Dean LT, Kennedy CE, et al. Social capital and utilization of immunization service: a multilevel analysis in rural Uttar Pradesh, India. SSM Popul Health 2020;10:100545.

22 Kawachi I, Subramanian SV, Kim D. Social capital and health. New York, London: Springer, 2008.

23 Palipudi KM, Morton J, Hsia J, et al. Methodology of the global adult tobacco survey - 2008-2010. Glob Health Promot 2016;23:3-23.

24 World Health Organization. Global youth tobacco survey (GYTS), 2009. Available: http://www.who.int/tobacco/surveillance/gyts/en/ [Accessed 5 Jul 2018].

25 Riley L, Guthold R, Cowan M, et al. The world Health organization stepwise approach to noncommunicable disease risk-factor surveillance: methods, challenges, and opportunities. Am J Public Health 2016;106:74-8.

26 Bandura A. Social foundations of thought and action: a social cognitive theory. NJ: Prentice-Hall, Englewood Cliffs, 1986.
27 McLeroy KR, Bibeau D, Steckler A, et al. An ecological perspective on health promotion programs. Health Educ $Q$ 1988;15:351-77.

28 Castro Y, Heck K, Forster JL, et al. Social and environmental factors related to smoking cessation among mothers: findings from the geographic research on wellbeing (grow) study. Am J Health Behav 2015;39:809-22.

29 Kowalewska A, Mazur J. Adolescent's perception of peer substance use in relation to social relationship and the neighbourhood social capital. Przegl Lek 2013;70:822-5.

30 Nagler EM, Sinha DN, Pednekar MS, et al. Social contextual factors and tobacco use among Indian teachers: insights from the Bihar school teachers' study. Prev Med 2015;74:24-30.

31 World Health Organization. A conceptual framework for action on the social determinants of health: debates, policy \& practice, case studies, 2010. Available: http://apps.who.int/iris/bitstream/10665/ 44489/1/9789241500852_eng.pdf [Accessed 14 Feb 2017].

32 Harpham T, Grant E, Thomas E. Measuring social capital within health surveys: key issues. Health Policy Plan 2002;17:106-11.

33 Bourdieu P. The Forms of Capital. In: Richardson J, ed. Handbook of theory and research for the sociology of education. Westport, Greenwood, 1986: 241-58. http://architecturalnetworks.research. mcgill.ca/assets/w06 bourdieu.pdf

34 Kawachi I, Kennedy BP, Glass R. Social capital and self-rated health: a contextual analysis. Am J Public Health 1999;89:1187-93.

35 Crone MR, Reijneveld SA, Willemsen MC, et al. Prevention of smoking in adolescents with lower education: a school based intervention study. J Epidemiol Community Health 2003:57:675-80.

36 Seid AK, Hesse M, Bloomfield K. 'Make it another for me and my mates': does social capital encourage risky drinking among the Danish general population? Scand J Public Health 2016;44:240-8.

37 Lundborg P. Social capital and substance use among Swedish adolescents--an explorative study. Soc Sci Med 2005;61:1151-8.

38 Brown TT, Scheffler RM, Seo S, et al. The empirical relationship between community social capital and the demand for cigarettes. Health Econ 2006;15:1159-72.

39 HCL Foundation. Project samuday, 2018. Available: http://www. hclfoundation.org/hcl-samuday [Accessed 1 Jul 2018].

40 HCL Foundation. HCL foundation, 2017. Available: http://www. hclfoundation.org/ [Accessed 5 Jul 2018].

41 International Institute for Population Sciences, Ministry of Health and Family Welfare. National family health survey final report: Uttar Pradesh, 2016. Available: http://rchiips.org/NFHS/NFHS-4Report. shtml [Accessed 16 Mar 2018].

42 International Institute for Population Sciences, ICF. India national family health survey NFHS-4 2015-16, 2017. Available: http:// dhsprogram.com/pubs/pdf/FR339/FR339.pdf [Accessed 27 Dec 2018].

43 International Institute for Population Sciences, ICF. National family health survey (NFHS-4) interviewer manual, 2014. Available: file:///C:/ Users/zabir/Documents/Dropbox/PHD/Hopkins/Thesis/Litarature/ India/NFHS-4\%20Interviewer\%20Manual.pdf [Accessed 12 Jun 2019].

44 Babalola S. Readiness for HIV testing among young people in northern Nigeria: the roles of social norm and perceived stigma. AIDS Behav 2007;11:759-69.

45 Koku EF. Desire for, and uptake of HIV tests by Ghanaian women: the relevance of community level stigma. J Community Health 2011;36:289-99.

46 McQuestion MJ. Endogenous social effects on intimate partner violence in Colombia. Soc Sci Res 2003;32:335-45.

47 Hasan MZ, Leoutsakos J-M, Story WT, et al. Exploration of factor structure and measurement invariance by gender for a modified shortened adapted social capital assessment tool in India. Front Psychol 2019;10:2641

48 Goldenberg M, Danovitch I, IsHak WW. Quality of life and smoking Am J Addict 2014;23:540-62.

49 Ataeiasl M, Sarbakhsh P, Dadashzadeh H, et al. Relationship between happiness and tobacco smoking among high schoo students. Epidemiol Health 2018;40:e2018009.

50 Institute of Medicine (US) Committee on Preventing Nicotine Addiction in Children and Youths. Social norms and the acceptability of tobacco use. National Academies Press (US), 1994. https://www. ncbi.nlm.nih.gov/books/NBK236769/

51 Tyrrell J, Genin N, Myslinski M. Freedom of choice and decisionmaking in health and social care: views of older patients with earlystage dementia and their carers. Dementia 2006;5:479-502. 
52 Daniel AB, Nagaraj K, Kamath R. Prevalence and determinants of tobacco use in a highly literate rural community in southern India. Natl Med J India 2008;21:163-5.

53 Rani M, Bonu S, Jha P, et al. Tobacco use in India: prevalence and predictors of smoking and chewing in a national cross sectional household survey. Tob Control 2003;12:4e-4.

54 Filmer D, Pritchett LH. Estimating wealth effects without expenditure data--or tears: an application to educational enrollments in states of India. Demography 2001;38:115-32.

55 Office of the Registrar General \& Census Commissioner. Census of India, 2011. Available: http://censusindia.gov.in/pca/cdb_pca_ census/Houselisting-housing-UP.html [Accessed 6 Apr 2017].

56 StataCorp. Stata statistical software: release 15, 2017. Available: https://www.stata.com/new-in-stata/ [Accessed 4 Nov 2017].

57 Muthén LK, Muthén BO. Mplus user's guide. Los Angeles, CA: Muthén \& Muthén, 2017

58 Maldonado G, Greenland S. Simulation study of confounderselection strategies. Am J Epidemiol 1993;138:923-36.

59 Ennett ST, Foshee VA, Bauman KE, et al. A social contextual analysis of youth cigarette smoking development. Nicotine Tob Res 2010;12:950-62.

60 Mead EL, Rimal RN, Ferrence R, et al. Understanding the sources of normative influence on behavior: the example of tobacco. Soc Sci Med 2014;115:139-43.

61 Basu S, Zuo X, Lou C, et al. Learning to be gendered: gender socialization in early adolescence among urban poor in Delhi, India, and Shanghai, China. J Adolesc Health 2017;61:S24-9.

62 Hebert LE, Bansal S, Lee SY, et al. Understanding young women's experiences of gender inequality in Lucknow, Uttar Pradesh through story circles. Int J Adolesc Youth 2020;25:1-11.

63 Moore G. Structural determinants of men's and women's personal networks. Am Sociol Rev 1990;55:726-35.

64 Albert-Lörincz E, Paulik E, Szabo B, et al. Adolescent smoking and the social capital of local communities in three counties in Romania. Gac Sanit 2019;33:547-553.

65 Pförtner T-K, De Clercq B, Lenzi M, et al. Does the association between different dimension of social capital and adolescent smoking vary by socioeconomic status? A pooled cross-national analysis. Int J Public Health 2015;60:901-10.

66 May S, West R, Hajek P, et al. Randomized controlled trial of a social support ('buddy') intervention for smoking cessation. Patient Educ Couns 2006;64:235-41.

67 Hennrikus D, Pirie P, Hellerstedt W, et al. Increasing support for smoking cessation during pregnancy and postpartum: results of a randomized controlled pilot study. Prev Med 2010;50:134-7.

68 Masho SW, Do E, Adekoya S. Social support and smoking during pregnancy. J Womens Health Care 2014;3.

69 Rapier R, McKernan S, Stauffer CS. An inverse relationship between perceived social support and substance use frequency in socially stigmatized populations. Addict Behav Rep 2019;10:100188.

70 Soulakova JN, Tang C-Y, Leonardo SA, et al. Motivational benefits of social support and behavioural interventions for smoking cessation. $J$ Smok Cessat 2018;13:216-26.

71 Westmaas JL, Bontemps-Jones J, Bauer JE. Social support in smoking cessation: reconciling theory and evidence. Nicotine Tob Res 2010;12:695-707.

72 Khubchandani J, Sharma M, Huston D, et al. Tobacco use related attitudes and behaviors in Indian adolescents: association with school-based prevention education. Health Promot Perspect 2017;7:128-33.

73 Sharma D, Goel S, Lal P. Education differential in relation to tobacco use and its predictors across different regions of India. Indian $J$ Cancer 2017;54:584-8.

74 Gilman SE, Martin LT, Abrams DB, et al. Educational attainment and cigarette smoking: a causal association? Int $J$ Epidemiol 2008;37:615-24.
75 Bandura A. Social cognitive theory: an agentic perspective, 2000.

76 Gonzalez-Barcala F-J, Pertega S, Sampedro M, et al. Impact of parental smoking on childhood asthma. J Pediatr 2013;89:294-9.

77 Pattenden S, Antova T, Neuberger M, et al. Parental smoking and children's respiratory health: independent effects of prenatal and postnatal exposure. Tob Control 2006;15:294-301.

78 McKay AJ, Patel RKK, Majeed A. Strategies for tobacco control in India: a systematic review. PLoS One 2015;10:e0122610.

79 Naslund JA, Kim SJ, Aschbrenner KA, et al. Systematic review of social media interventions for smoking cessation. Addict Behav 2017;73:81-93.

80 Government of India, Ministry of Health and Family Welfare. mCessation programme: quit tobacco for life, 2015. Available: https://www.nhp.gov.in/quit-tobacco-about-programme_mtl [Accessed 7 Jul 2018].

81 Cohen JE, Brown J, Washington C, et al. Do cigarette health warning labels comply with requirements: a 14-country study. Prev Med 2016;93:128-34

82 Datta K. Tobacco use in India: It's a cultural practice, 2016. Available: http://www.asianage.com/india/tobacco-use-india-it-s-culturalpractice-762 [Accessed 17 Dec 2018].

83 Kelly BC, Vuolo M, Frizzell LC, et al. Denormalization, smoke-free air policy, and tobacco use among young adults. Soc Sci Med 2018;211:70-7.

84 Lindström M, Giordano GN. Changes in social capital and cigarette smoking behavior over time: a population-based panel study of temporal relationships. Nicotine Tob Res 2016;18:2106-14.

85 Sheikhattari P, Apata J, Kamangar F, et al. Examining smoking cessation in a community-based versus clinic-based intervention using community-based participatory research. J Community Health 2016;41:1146-52.

86 Steyn K, Hoffman M, Levitt NS, et al. Community-based tobacco control program: the Mamre study, a demonstration project. Ethn Dis 2001;11:296-302.

87 Ministry of Health and Family Welfare, Government of India. Village health sanitation \& nutrition committee. National health mission, 2014. Available: http://nhm.gov.in/communitisation/village-healthsanitation-nutrition-committee.html [Accessed 8 Jul 2018].

88 National Resource Center For Tobacco Control. Uttar Pradesh. National resource center for tobacco control, 2020. Available: https:// www.rctcpgi.org/uttar-pradesh/

89 Ministry of Electronics \& Information Technology, Government of India. Ayushman Bharat - national health protection mission, 2018. Available: https://www.india.gov.in/spotlight/ayushman-bharatnational-health-protection-mission [Accessed $12 \mathrm{Jul} 2018$ ].

90 Ministry of Rural Development, Government of India. Annual reports of national institute of rural development and panchayati Raj, 2018. Available: http://nirdpr.org.in/annualreports.aspx [Accessed 14 Nov 2019]

91 Aayog N. Annual report 2018-19, 2018. Available: https://niti.gov.in/ sites/default/files/2019-11/AnnualReport2019.pdf [Accessed 16 Nov 2019].

92 Spary C. Gender, development, and the state in India. Routledge, 2019.

93 Yadav S, Arokiasamy P. Understanding epidemiological transition in India. Glob Health Action 2014;7:23248.

94 Al Kibria GM, Swasey K, Hasan MZ, et al. Prevalence and factors associated with underweight, overweight and obesity among women of reproductive age in India. Glob Health Res Policy 2019;4:24.

95 Abariga SA, Khachan H, Al Kibria GM. Prevalence and determinants of hypertension in India based on the 2017 ACC/AHA guideline: evidence from the India national family health survey. Am J Hypertens 2020;33:252-60. 